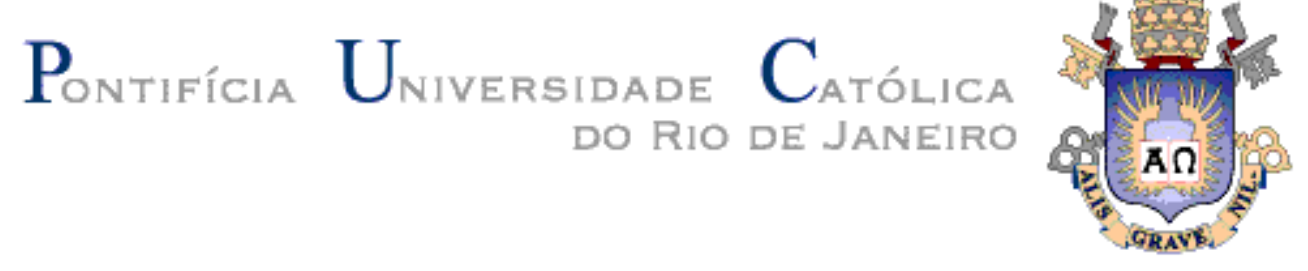

Bárbara Lúcia Silva Santos

Conselho Tutelar: entre o exercício da democracia e o clientelismo

Dissertação de Mestrado

Dissertação apresentada ao Programa de Pósgraduação em Serviço Social da PUC-Rio como requisito parcial para obtenção do título de Mestre em Serviço Social

Orientador: Rafael Soares Gonçalves

Rio de Janeiro Maio de 2011 


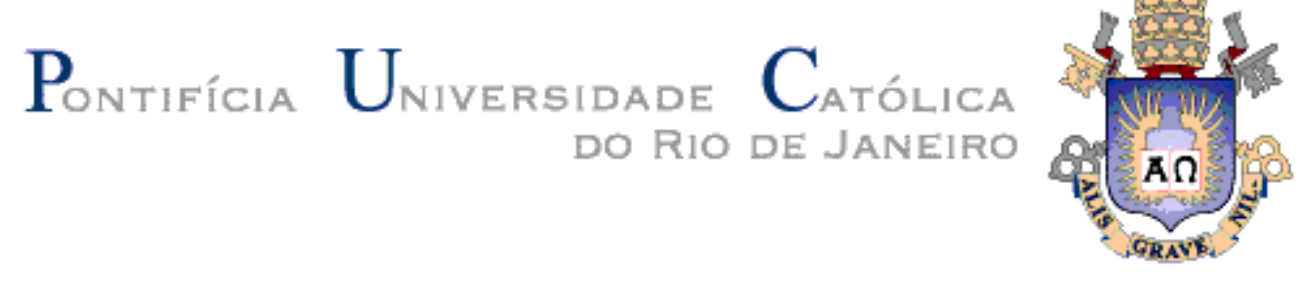

Bárbara Lúcia Silva Santos

\section{Conselho Tutelar: entre o exercício da democracia e o clientelismo}

Dissertação apresentada como requisito parcial para obtenção do grau de Mestre pelo Programa de PósGraduação em Serviço Social do Departamento de Serviço Social do Centro de Ciências Sociais da PUCRio. Aprovada pela Comissão Examinadora abaixo assinada.

Prof. Rafael Soares Gonçalves

Orientador

Departamento de Serviço Social - PUC-Rio

Profa. Andréia Clapp Salvador

Departamento de Serviço Social - PUC-Rio

Profa. Maria Helena Tenório de Almeida UERJ

Profa. Mônica Herz Vice-Decana de Pós-Graduação do Centro de Ciências Sociais - PUC-Rio 
Todos os direitos reservados. É proibida a reprodução total ou parcial sem a autorização da universidade, da autora e do orientador.

\section{Bárbara Lúcia Silva Santos}

Graduou-se em Serviço Social pela Pontifícia Universidade Católica do Rio de Janeiro em 2000.

Trabalhou durante três anos como assistente social do Conselho Tutelar de Duque de Caxias. Atualmente é assistente social do Instituto Nacional de Traumatologia e Ortopedia do Rio de Janeiro

Ficha Catalográfica

Santos, Bárbara Lúcia Silva

Conselho tutelar: entre o exercício da democracia e o clientelismo / Bárbara Lúcia Silva Santos; orientador: Rafael Soares Gonçalves. - 2011.

95 f. : il. (color.) ; $30 \mathrm{~cm}$

Dissertação (mestrado)-Pontifícia Universidade Católica do Rio de Janeiro, Departamento de Serviço Social, 2011

Inclui bibliografia.

1. Serviço social - Teses. 2. Conselho tutelar. 3. Participação social. 4. Clientelismo.

I. Gonçalves, Rafael Soares. II. Pontifícia Universidade Católica do Rio de Janeiro. Departamento de Serviço Social. III. Título. 


\section{Agradecimentos}

Em primeiro lugar a Deus, pois toda a minha vida é prova de sua misericórdia e do seu amor.

A minha mãe, mulher de fibra que tem dado exemplo de que as batalhas são momentos a ser superados frente as dificuldades da vida.

Ao meu marido pela força, companhia, amor e cuidados dispensados. Obrigado por também acreditar no meu potencial e investir na minha formação de todas as formas.

A minha irmã Dayana e ao meu cunhado Joelson, vocês são pessoas fundamentais na minha vida.

A vovó Maria Joana (In Memorian), você faz muita falta! Uma pena não estar viva pra ver o cumprimento de mais esta etapa.

A professora Inez Stampa, apesar do pouco contato, foi um privilégio conhecê-la

Ao meu orientador Rafael por me auxiliar nessa dissertação, parecia algo impossível, mas nada é impossível ao que crê, não é?

A professora Andréia Clapp, mais uma vez nos encontramos em momentos tão parecidos. Obrigada por fazer parte da minha jornada acadêmica.

A Banca Examinadora pelas orientações e dicas, nesse processo acadêmico.

A CAPES e a PUC Rio pelo apoio e investimento no meu processo de formação acadêmica.

A minha turma do Mestrado, as trocas foram fundamentais para chegar a este resultado. Edith, Viviane, Juliana, Aline Batista, Fernando, Wagner, na etapa final senti falta do lanche no Bar dos Funcionários. Beijos a todos.

A amiga Rosimar que desde a graduação tem me ajudado nos inúmeros momentos da minha vida.

A amiga Ana Maria pelas dicas. É um orgulho ter te conhecido. Também as amigas do Into pela força.

Agradeço também aos conselheiros tutelares, e aos que participaram da pesquisa para que este estudo fosse realizado.

Enfim, quero agradecer a todos que contribuíram para que eu chegasse até aqui.

A todos vocês meus sinceros agradecimentos 


\section{Resumo}

Santos, Bárbara Lúcia Silva; Gonçalves, Rafael Soares. Conselho Tutelar: Entre o exercício da democracia e o clientelismo. Rio de Janeiro, 2011. 95p. Dissertação de Mestrado - Departamento de Serviço Social, Pontifícia Universidade Católica do Rio de Janeiro.

O Conselho Tutelar criado a partir do Estatuto da Criança e do Adolescente em 1990 é um órgão que nasceu com a perspectiva de participação da comunidade local, no zelo aos direitos da criança e do adolescente. Apesar desta inovação que é fruto da luta dos movimentos sociais das décadas de 1970/80, o que tem sido observado no cotidiano é a presença de práticas políticas opostas dentro de espaços que foram constituídos visando o protagonismo da Sociedade Civil. A presente dissertação teve como objetivo analisar a presença de dois projetos políticos antagônicos (Projeto Democrático $\mathrm{X}$ Projeto Conservador) no Conselho Tutelar, tendo como foco o processo de escolha dos conselheiros tutelares, que no município pesquisado ocorre através de eleição direta. $\mathrm{O}$ campo de pesquisa foi o Conselho Tutelar de Duque de Caxias, hoje composto por três Conselhos tutelares que atendem os quatros distritos municipais. Foram entrevistados: um conselheiro em cada Conselho; um assistente social, integrante da equipe técnica de um dos Conselhos Tutelares e um representante da comunidade local que participou do último processo de escolha para Conselheiro Tutelar. A partir da pesquisa identificamos características que fortalecem tanto as práticas políticas tradicionais, quanto as democráticas. Por fim também analisamos como os conselheiros percebem a questão da participação: i) da comunidade local no Conselho Tutelar e ii) de sua inserção numa instituição ligada à temática da criança e do adolescente, sendo este último um dos critérios para concorrer ao processo de escolha.

\section{Palavras-Chave}

Conselho Tutelar; participação social; clientelismo. 


\section{Abstract}

Santos, Barbara Lucia Silva; Gonçalves, Rafael Soares (Advisor). Guardianship Council: Between the Practice of Democracy and Clientelism. Rio de Janeiro, 2011. 95p. MSc. Dissertation - Departamento de Serviço Social, Pontifícia Universidade Católica do Rio de Janeiro.

The Guardianship Councils were created in 1990 based on The Child and Adolescent Statute (Estatuto da Criança e do Adolescente). It is an organization that, supported by local community, cares about the rights of children and adolescents. This innovation is a result of social movements' struggles of the 1970's and 1980's but, in reality, opposite policies are present in established places for civil society. This dissertation analyses two opposite political projects (Democratic project Vs. Conservative project) at Guardianship Council concentrating on the choice process of the guardianship counselors, which at the studied county happens through direct election. The research field was the Guardianship Council from Duque de Caxias in which there are three guardianship counselors who advice the population of the four districts of the county. In each Guardianship Council, one guardianship counselor was interviewed. One social assistant from the technical team and one local community representative, who participated in the last election, were also interviewed. After researching, we identified some characteristics that confirm not only the traditional policies but also the democratic ones. Concluding, we also analyzed how the guardianship counselors understand: i) local community participation at Guardianship Council and ii) its inclusion in an organization connected to children and adolescents' interests, and this second point is a criterion for standing for elections.

\section{Keywords:}

Guardianship Council; social participation; Clientelism. 


\section{Sumário}

1. Introdução

2. A consolidação dos Conselhos no Brasil e no Mundo 14

2.1. Algumas experiências de Conselhos na história mundial 14

2.2. Os Conselhos no Brasil

3. Os Conselhos de Direitos no Estatuto da Criança e do Adolescente

3.1. CONANDA - Conselho Nacional de Direitos da Criança e do Adolescente

3.2. CEDCA - Conselho Estadual de Direitos da Criança e do Adolescente

3.3. CMDCA - Conselho Municipal de Direitos da Criança e do adolescente

3.4. O Conselho Tutelar 34

3.4.1. O processo de escolha do conselheiro 42

4. Os conselhos: Impasses e dilemas na efetivação do projeto democrático

4.1. Clientelismo e democracia: projetos antagônicos caminhando numa mesma direção

5. O Conselho Tutelar em Duque de Caxias: entre a garantia da participação democrática e o exercício do clientelismo 62

5.1. Clientelismo $X$ Participação: $A$ análise dos discursos

5.1.1. Clientelismo $X$ Participação: $A$ visão de outros atores sobre o mesmo fenômeno

6. Conclusões 
Referências Bibliográficas

Anexos 